\title{
Influence of strain rate on ductile versus brittle fracture for ductile cast iron EN-GJS-500-14 in $V$-notch three-point bending tests
}

\author{
Maqsood Ahmad ${ }^{1, *}$, Joachim Lindkvist ${ }^{1}$, and Magnus Andersson ${ }^{2}$ \\ ${ }^{1}$ Volvo Group Trucks Technology, Base Engine \& Materials Technology, Volvo Group, SE-40508, \\ Gothenburg, Sweden \\ ${ }^{2}$ Volvo Construction Equipment, Virtual Product Development, Volvo CE, SE-36331, Braås, Sweden
}

\begin{abstract}
Three point bending tests on V-notched specimens machined from a component cast in EN-GJS 500-14 nodular iron solid solution strengthened by silicon have been carried out. The $3 \mathrm{P}$ bending tests were performed at different stroke speeds $\left(10^{-3} \sim 10^{2} \mathrm{~mm} / \mathrm{s}\right)$. The resulting strain rates at the $\mathrm{V}$ notch varied in the range of $1 \cdot 10^{-4} \sim 5,8 \mathrm{~s}^{-1}$. The fracture surface of $3 \mathrm{P}$ bending tests was quantified in terms of ductile and brittle fracture using Scanning Electron Microscope (SEM). EN-GJS 500-14 has an increased brittle behavior with increasing strain rate. Predominately ductile fracture was observed for the strain rates $1 \cdot 10^{-4} \sim 4 \cdot 10^{-2} s^{-1}$. At the strain rate of about $1 \mathrm{~s}^{-1}$ more significant change in ductile to brittle fracture is seen. The $3 \mathrm{P}$ bending tests at $-15^{\circ} \mathrm{C}$ showed predominately brittle fracture for the strain rates investigated $3,6 \cdot 10^{-2} \sim 2,3 \mathrm{~s}^{-1}$.
\end{abstract}

\section{Introduction}

Solid solution strengthened ductile irons are specified in EN 1563:2012 as a new family of ductile irons based on ferritic matrix and solution strengthened mainly by silicon. This group of ductile irons provide an attractive combination of mechanical and machining properties [1-2]

During the last couple of years a few failures have been experienced in solid solution strengthened spheroidal graphite iron parts at relatively short life. There were some preliminary indications that the components failed without significant plastic deformation and strain rate may have influenced the fracture. Further in a recent paper Ikeda [3] have shown that the solid solution strengthened ductile iron change from ductile to brittle fracture at the critical strain rate of $2,5 \times 10^{-1}$. In order to better understand the cause for the brittle failure three point bending tests on $\mathrm{V}$-notched specimens at different stroke speeds $\left(10^{-3} \sim 10^{2} \mathrm{~mm} / \mathrm{s}\right)$ have been carried out. The test samples were machined from a component cast in EN-GJS 500-14 nodular iron solid solution strengthened by silicon. The strain rates

* Corresponding author: maqsood.ahmad@ volvo.com 
at the $\mathrm{V}$ notch were calculated using the relationship $\dot{\varepsilon}_{n}=6 h Q \dot{w} / L^{2}$ [4]. The fracture surfaces were analyzed and compared to each other and to the fracture surface from the component.

\section{Material and experimental details}

\subsection{Extraction of test samples}

A total of 2 parts horizontally cast in material EN-GJS 500-14 were obtained. The quality of the material was initially controlled on two components from the same batch ( $~ 80$ pcs) as the one that failed in the field. This was made at the centre of the parts in the positions shown in figure 3.

The locations of test samples for $\mathrm{V}$-notched three-point bending specimens are displayed in figure 1. A total of 9 samples were extracted from each component. The specimens are marked as 1-1 to 1-9 and 2-1 to 2-9.

The size of the Charpy V-notch specimens is $10 \mathrm{~mm} \times 10 \mathrm{~mm} \times 55 \mathrm{~mm}$ and the depth of the notch is $2 \mathrm{~mm}$. The dimensions are in accordance with SS-EN ISO 148-1:2010(E) Metallic materials - Charpy pendulum impact test.
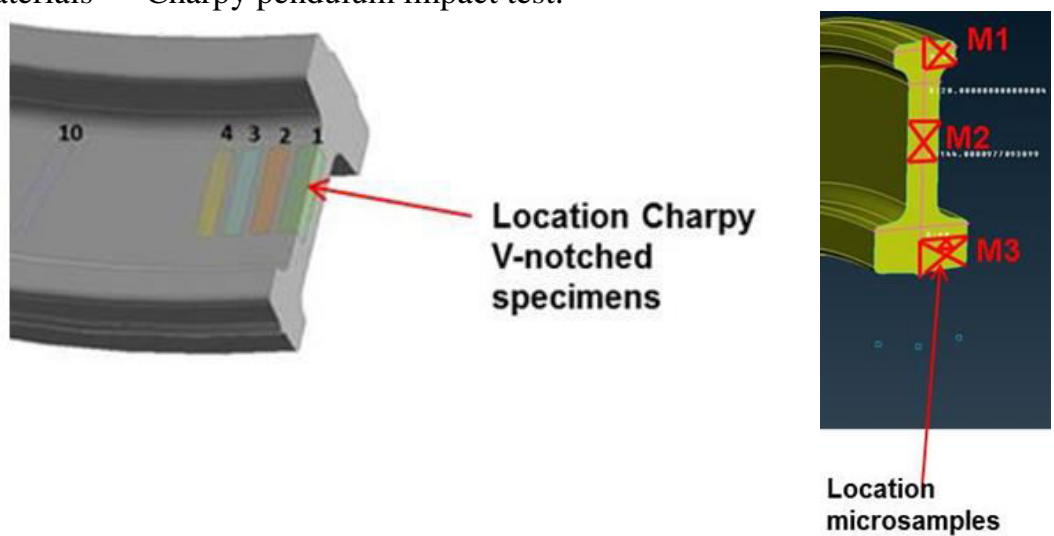

Fig. 1. The location of test samples for microstructure analysis and three-point bending V-notched specimens on component.

\subsection{Microstructural Investigation}

Microstructure (including graphite appearance, nodularity, nodule count, structure in matrix and carbide content), hardness (HBW 5/750) and chemical compositions were investigated and compared to the Volvo standard for nodular iron STD 310-0004 for grade VISG 500/14 and EN-GJS-500-14. Nodularity and nodule count were measured using image analysis on 36 images with a resolution of $0,96 \mu \mathrm{m} / \mathrm{pixel}$ and a total measured area of at least 37,1 $\mathrm{mm}^{2}$. Samples were etched in Nital and the amount of pearlite in the matrix and the carbide content were qualitatively estimated by microscopy.

All 3P-bending samples were evaluated in Scanning Electron Microscope (SEM). A high resolution overview picture was taken at $\sim 13 \mathrm{x}$ magnification from each sample. The percentage of cleavage fractures to ductile/dimpled fracture was calculated from creating a binary layer on each picture in Photoshop. The grains/areas showing cleavage fracture(s) were marked black and the percentage was calculated from comparing the amount of black or white pixels.

\subsection{Three-point bending tests}


Three-point bending tests were performed using a 100/4 kN MTS hydraulic test machine (UMM8) at room temperature. The tests were carried out in the range of stroke speed $10^{-3}$ $\sim 10^{2} \mathrm{~mm} / \mathrm{s}$.

The strain rate $\dot{\varepsilon}_{n}$ at the notch root is calculated using the relationship shown below;

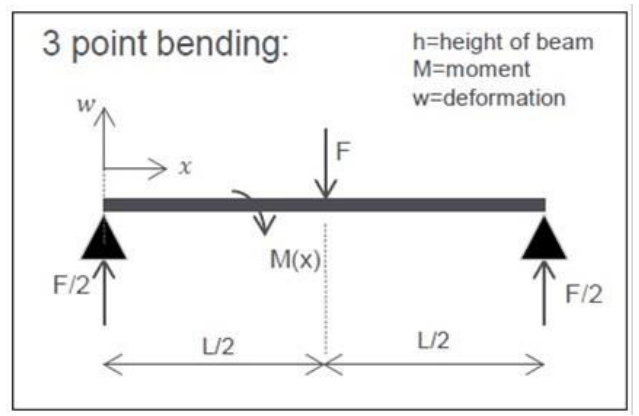

$$
\begin{aligned}
\frac{\varepsilon}{w} & =\frac{F L}{8 E I} h \cdot \frac{48 E I}{F L^{3}}=\frac{6 h}{L^{2}} \rightarrow \\
\varepsilon & =\frac{6 h}{L^{2}} w
\end{aligned}
$$

Nominal strain rate: $\dot{\varepsilon}=\frac{6 h}{L^{2}} \dot{w}$

Notch strain rate: $\dot{\varepsilon}_{n}=\frac{6 h Q}{L^{2}} \dot{W}$

The Stress intensification factor, Q, (relating nominal strain to notch strain) is assumed to be $Q=1.94$ using Tresca's yielding criterion according to [4].

\section{Results}

\subsection{Microstructure}

The microstructure varied quite much over the cross section of the I-beam-shape. The nodularity varied from $78-88$ and the nodule count from 184 to 333 , from position M2 to M1, i.e. position M2 showed the worst condition. The positions M1, M2 and M3 are defined in figure 1 . The reason for the poor nodularity score in M2 was poor nodule shape, micro-shrinkage and a significant amount of $\mathrm{MgO}$ in intercellular boundaries that are included when running the computer macro. The pearlite content in the matrix was less than $1 \%$ in position M1 and M2 but $1-2 \%$ in position M3. The content of free carbides was very low, $<<1 \%$. For all results see Table 1

All samples show casting defects at the surface, but sample M2 and M3 showed the worst conditions. The hardness was homogeneous with average values of 187 to $190 \mathrm{HBW}$ 5/750. For simplicity the 3P-bending samples was decided to be taken in the web area.

\begin{tabular}{|c|c|c|c|c|}
\hline & $\begin{array}{c}\text { Nodularity } \\
{[\%]}\end{array}$ & $\begin{array}{c}\text { Nodule count } \\
{\left[\mathrm{No} / \mathrm{mm}^{2}\right]}\end{array}$ & $\begin{array}{c}\text { Pearlite content } \\
{[\%]} \\
\end{array}$ & $\begin{array}{c}\text { Hardness } \\
{[\mathrm{HBW} \text { 5/750] }}\end{array}$ \\
\hline $1 \mathrm{M} 1$ & 88 & 320 & $<<1$ & 190 \\
\hline $1 \mathrm{M} 2$ & 78 & 184 & $<1$ & N/A \\
\hline $1 \mathrm{M} 3$ & 85 & 244 & $\sim 1$ & 189 \\
\hline $2 \mathrm{M} 1$ & 88 & 333 & $<<1$ & 189 \\
\hline $2 \mathrm{M} 2$ & 80 & 183 & $<1$ & 187 \\
\hline $2 \mathrm{M} 3$ & 81 & 203 & $1-2$ & N/A \\
\hline STD 310-004 & $\geq 80$ & - & $\leq 5$ & $185-215$ \\
\hline EN-1563* & - & - & - & - \\
\hline
\end{tabular}

Table 1: Results from microscopical investigation of components

* No structural requirements, only mechanical.

\subsection{Chemical Analysis}


The chemical composition was measured using spark OES for all elements except for $\mathrm{Mg}$ that was measured using flame atomic absorption spectrometry. The result can be seen in table 2. All elements are within recommended limits. The difference in $\mathrm{C}$ content is nevertheless significant between the two non-used cross stays while all other elements are basically the same. In component 2 the high carbon content made the carbon equivalent exceed 4,3 and is hence hypereutectic. No real difference was however seen in the graphite morphology between the parts except for a slight tendency for carbon flotation in sample 2_M3.

Table 2: Chemical composition (wt\%) of component 1 and 2.

\begin{tabular}{|c|c|c|c|c|c|c|c|c|c|c|c|c|c|c|}
\hline Sample & Material & C & Si & $\mathrm{Mn}$ & $\mathbf{P}$ & s & $\mathrm{Cr}$ & $\mathrm{Ni}$ & Mo & $\mathrm{Cu}$ & Sn & $\mathrm{Ti}$ & $\mathrm{Mg}$ & Cekv \\
\hline Sample 1 & EN-GJS-500-14 & 3,16 & 3,64 & 0,11 & 0,032 & $<0,005$ & 0,03 & 0,01 & $<0,01$ & 0,08 & $<0,005$ & 0,023 & 0,034 & 4,09 \\
\hline Sample 2 & EN-GJS-500-14 & 3,47 & 3,66 & 0,11 & 0,033 & $<0,005$ & 0,03 & 0,01 & $<0,01$ & 0,08 & $<0,005$ & 0,024 & 0,034 & 4,40 \\
\hline EN 1563:2012 & & - & nom & $\max$ & $\max$ & & & & & & & & & \\
\hline & EN-GJS-500-14 & - & 3,80 & 0,50 & 0,050 & & & & & & & & & \\
\hline $\mathrm{Cekv}=\mathrm{C}+\mathrm{P} / 2+\mathrm{Si} / \mathrm{L}$ & & & & & & & & & & & & & & \\
\hline
\end{tabular}

\subsection{Three-point bending test results}

\subsubsection{Appearance fracture surface 3P-bending samples}

An increase in percentage cleavage fractures with increased stroke speed can be seen visually (the amount of shiny spots increases) on the fracture surfaces (figure 2). Only one sample (stroke speed $39 \mathrm{~mm} / \mathrm{s}$ ) have a somewhat similar appearance as Figure 9 in ASTM E23-16b for Charpy V-notch test bars. When using the binary pictures (figure 3) a better comparison was achieved and the calculated percentages are seen.
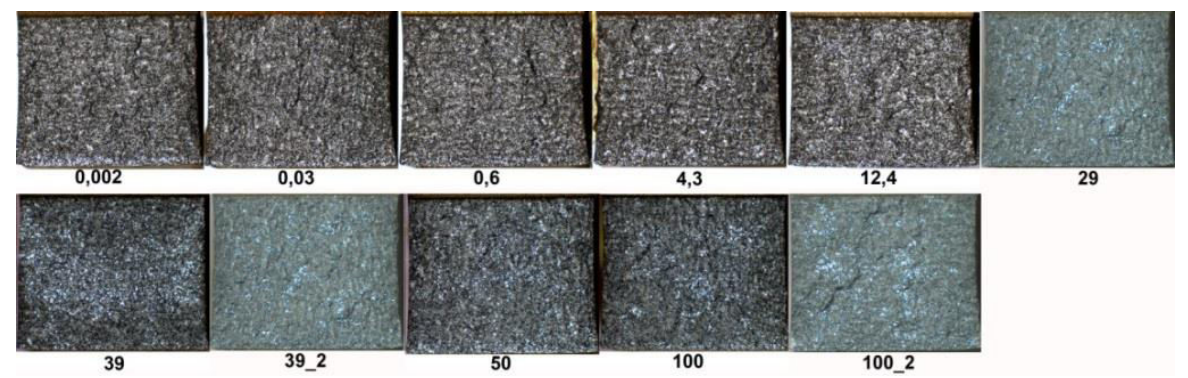

Fig. 2. Optical pictures of the fracture surfaces. Fracture start at the top of each picture. The numbers below each picture show stroke speed used in 3P bending tests.

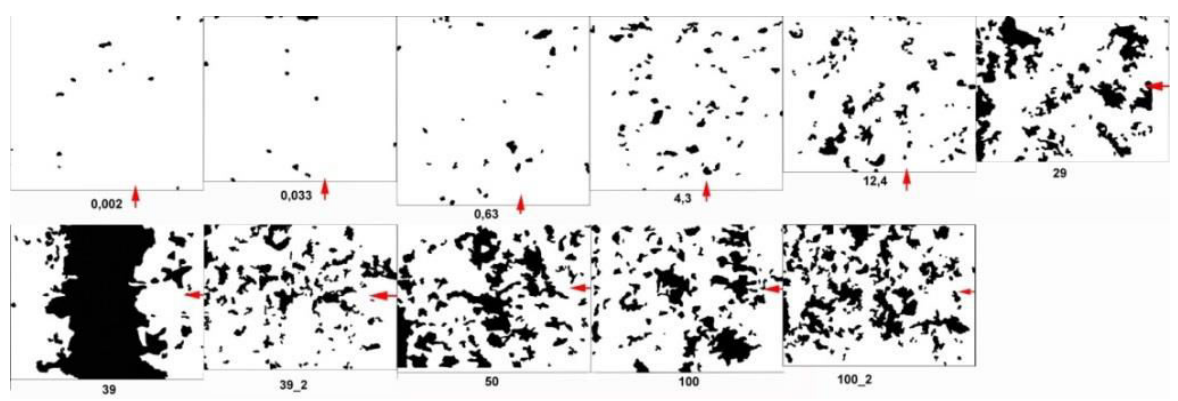

Fig. 3. Binary picture created from SEM overview pictures. One area for each sample (stroke speed). Black colour represents cleavage fractures. The red arrow marks the direction of fracture for each sample. 


\subsubsection{Three-point bending test results}

The relationship between strain rate and stroke speed is $\dot{\varepsilon}_{n}=6 h Q \dot{w} / L^{2}$. Table 3 summarizes the results of $3 \mathrm{P}$-bending tests showing maximum load, percentage of ductile and brittle failure. Load versus displacement curves are displayed in figure 4 . One of the samples with ID 1-9 and loading rate $39 \mathrm{~mm} / \mathrm{s}$ showed obvious unstable crack growth with $48 \%$ brittle failure. The maximum load in principal increases with the strain rate for the tests conducted at room temperature.

Absorbed energy was also calculated as the area under the load-displacement curves. The total absorbed energy $E_{t}$ can be divided into as the energy for crack initiation $E_{i}$ and energy for crack propagation $E_{p}$. The area under the curve up to the point of maximum load represents energy for crack initiation $E_{i}$, while the remaining area represents crack propagation energy $E_{p}$. The absorbed energies are plotted in figure 5. It can be seen that the initiation energy is nearly constant about $4 \mathrm{~J}$, for the tests at RT. However, when the temperature decreases to $-15^{\circ} \mathrm{C}$, the fracture show almost brittle failure with a total energy less than $4 \mathrm{~J}$, figure 5 (right graph).

Table 3. Summary 3-point bending V-notched specimens tests at RT and at $-15^{\circ} \mathrm{C}$.

\begin{tabular}{|c|c|c|c|c|c|c|}
\hline Specimen & $\left.\mathrm{T}^{\circ} \mathrm{C}\right]$ & ${\text { Strain rate }\left[\mathbf{s}^{-1}\right]}^{-1}$ & Speed $[\mathrm{mm} / \mathrm{s}]$ & $\max$ Load [KN] & Ductile \% & Brittle \% \\
\hline $2-3$ & 22 & $1.00 \mathrm{E}-04$ & 0.0017 & 10.23 & 99.5 & 0.5 \\
\hline $2-2$ & 22 & $1.90 \mathrm{E}-03$ & 0.0326 & 10.69 & 99.3 & 0.7 \\
\hline $1-5$ & 22 & $3.64 \mathrm{E}-02$ & 0.625 & 11.12 & 98.3 & 1.7 \\
\hline $2-7$ & 22 & $2.50 \mathrm{E}-01$ & 4.30 & 11.54 & 95.5 & 4.5 \\
\hline $1-2$ & 22 & $7.23 \mathrm{E}-01$ & 12.4 & 11.67 & 92.5 & 7.5 \\
\hline $2-8$ & 22 & $1.70 \mathrm{E}+00$ & 29.2 & 11.56 & 78 & 22 \\
\hline $1-7$ & 22 & $2.27 \mathrm{E}+00$ & 39.0 & 11.4 & 84 & 16 \\
\hline $1-9$ & 22 & $2.27 \mathrm{E}+00$ & 39.0 & 11.97 & 52 & 48 \\
\hline $2-6$ & 22 & $2.91 \mathrm{E}+00$ & 50.0 & 11.86 & 71 & 29 \\
\hline $1-1$ & 22 & $5.82 \mathrm{E}+00$ & 100 & 11.65 & 74 & 26 \\
\hline $2-1$ & 22 & $5.82 \mathrm{E}+00$ & 100 & 11.65 & 79 & 21 \\
\hline $2-9 \mathrm{~T}$ & -15 & $3.64 \mathrm{E}-02$ & 0.625 & 11.33 & 12.5 & 87.5 \\
\hline $1-8 \mathrm{~T}$ & -15 & $2.50 \mathrm{E}-01$ & 4.29 & 11.42 & 8.6 & 91.4 \\
\hline $1-4 \mathrm{~T}$ & -15 & $7.22 \mathrm{E}-01$ & 12.4 & 11.57 & 7.2 & 92.8 \\
\hline $1-3 \mathrm{~T}$ & -15 & $2.27 \mathrm{E}+00$ & 39.0 & 11.38 & 6.4 & 93.6 \\
\hline
\end{tabular}
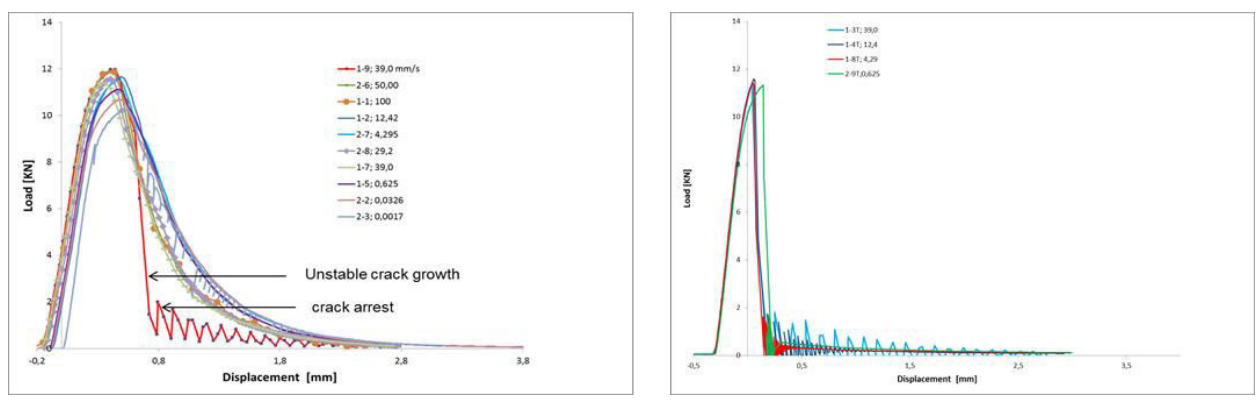

Fig. 4. Load versus displacement curves for the samples tested at various stroke speeds. Left graph tests at RT, right test at $-15^{\circ} \mathrm{C}$. 

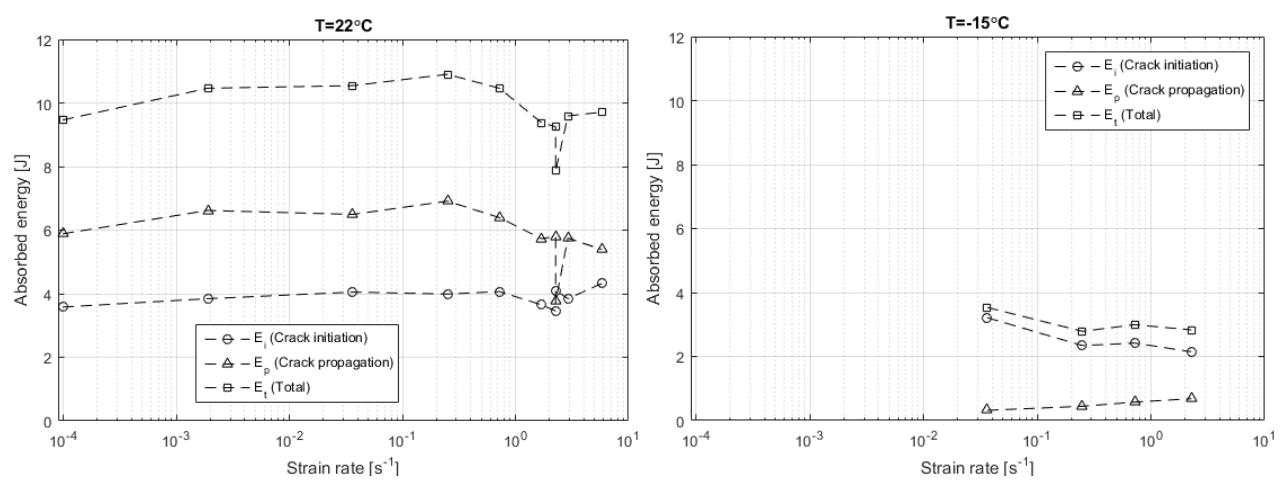

Fig. 5. Influence of strain rate on the absorbed energy. Left graph tests at RT, right test at $-15^{\circ} \mathrm{C}$.

Figure 6 shows an example of mixed mode fracture for the specimen (1-9) tested at RT and at stroke speed $39 \mathrm{~mm} / \mathrm{s}$. It was not possible to achieve more than about 20 to $30 \%$ brittle fracture at the RT tests, except for the one specimen with $48 \%(39 \mathrm{~mm} / \mathrm{s}$ in displacement). The servo hydraulic load frame allow a maximum stroke speed of 100 $\mathrm{mm} / \mathrm{s}$, therefore one additional test was performed using Charpy apparatus consisting of a pendulum. The absorbed energy measured was $4 \mathrm{~J}$. The result of Charpy impact test is plotted in figure 7 (left) together with $3 \mathrm{P}$ bending tests. For Charpy test the total absorbed energy appear to be the same as the crack initiation energy and no propagation energy. One additional Charpy test at $-15^{\circ} \mathrm{C}$ is included from the ref [1]. The fracture surface for the RT Charpy impact tests is shown in figure 8 (right), almost entirely brittle cleavage fracture (around $98 \%$ brittle).
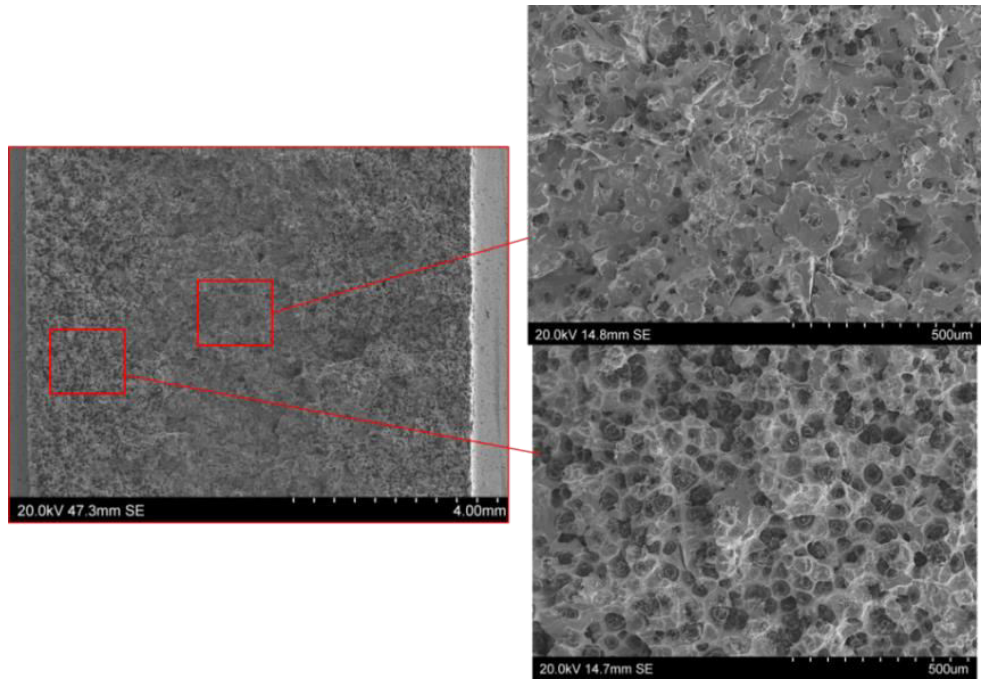

Fig. 6. Fracture surface of (1-9) test specimen at stroke speed $39 \mathrm{~mm} / \mathrm{s}$, overview picture-left, cleavage fracture-top and ductile fracture-bottom picture. 

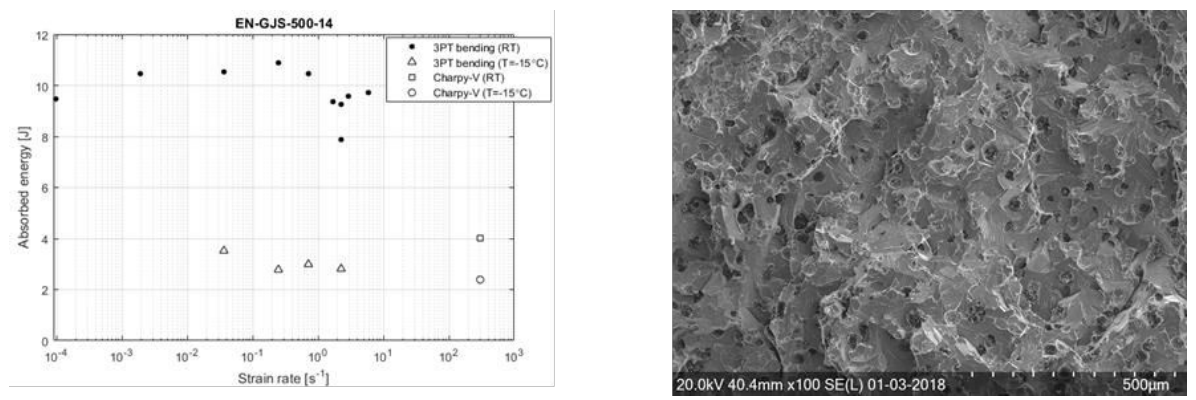

Fig. 7. Comparison of strain rate effect on the absorbed energy at room temperature and at $-15^{\circ} \mathrm{C}-\mathrm{left}$ graph . Two Charpy tests are included. 100\% brittle fracture in the Charpy impact sample-right.

The ductile fracture surface ratio for GJS 500-14 is plotted in figure 8. The corresponding data for the SSFDI500 from [3] is shown in figure $8 \mathrm{~b}$. The ductile fracture ratio is nearly constant for the strain rates $1 \times 10^{-4} \sim 4 \times 10^{-2} \mathrm{~s}^{-1}$, at the strain rate of $1 \mathrm{~s}^{-1}$ more significant change in ductile fracture ratio can be observed. As mentioned earlier for only one of the sample we observed about $50 \%$ brittle failure, other samples show brittle failure in the range of 20 to $30 \%$. In comparison for the SSFD1500 with 3,72\% Si, a more abrupt change at strain rate of $2,5 \times 10^{-1}$ can be observed.

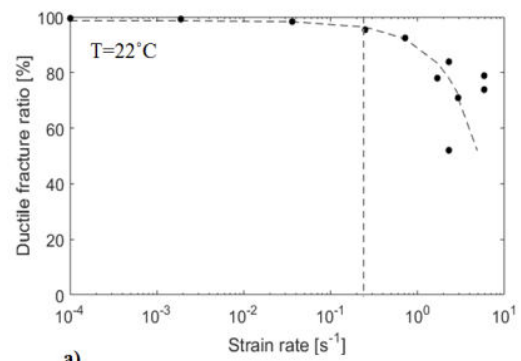

a)

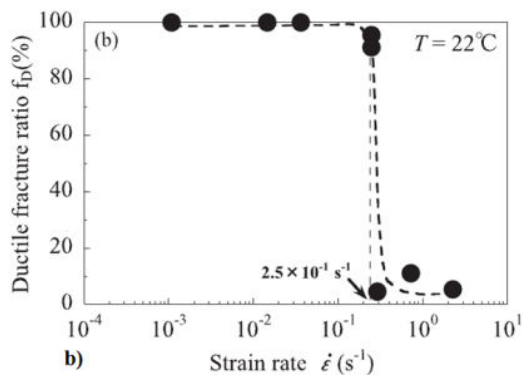

Fig. 8a-b. Effect of strain rate on ductile fracture ratio, GJS 500-14 Fig (a) and SSFDI500 Fig (b) from [3].

\section{Discussions}

The energy measured in Charpy tests is not that useful in calculation of structural components instead fracture toughness is more useful material property for design calculations. Wallin [6] has developed an approximate relation between $K_{J I C}$ and $C_{v}$ shown as :

$$
K_{J I C} \approx 180 \mathrm{MPa} \sqrt{m}\left(\frac{C_{v}}{100 J}\right)^{0.4}
$$

In figure 9 measured energies from 3P bending tests are plotted as vertical lines, green line at $10 \mathrm{~J}$ for ductile failure and blue line for mixed mode fracture at RT. The red line at 3,5 J representing complete brittle failure at $-15^{\circ} \mathrm{C}$. At present there is a lack of dynamic toughness data for the ductile iron GJS 500-14 as a function of strain rate and test temperature. The graph in figure 9 show at minus $15^{\circ} \mathrm{C}$ we could expect a minimum toughness of as low as $35 \mathrm{MPa}-\sqrt{\mathrm{m}}$. 


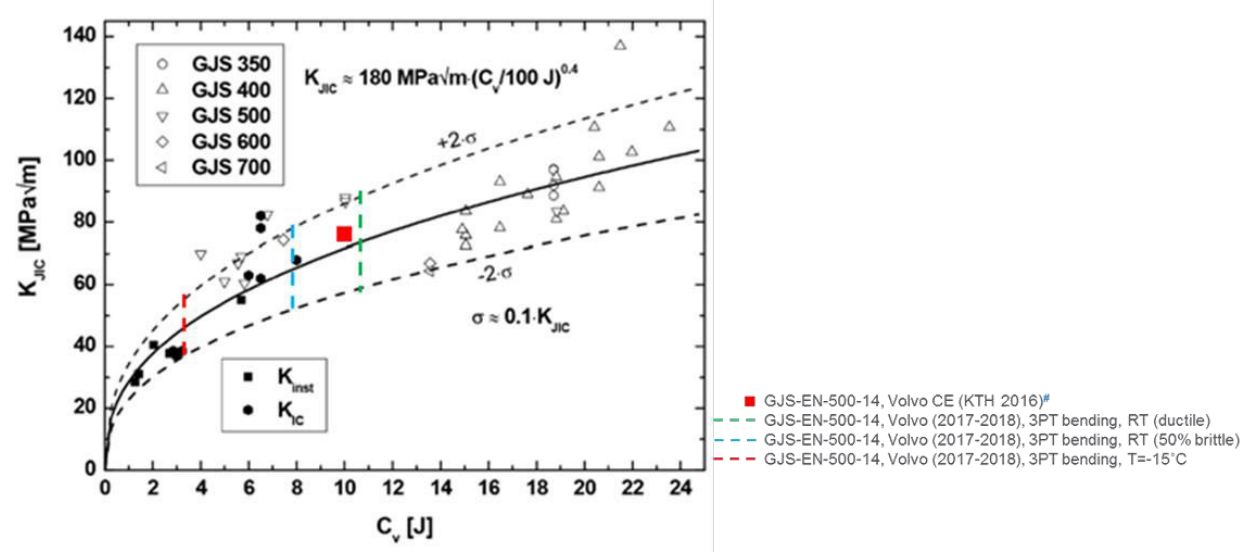

Fig. 9. Relation between $\boldsymbol{K}_{\boldsymbol{J} I \boldsymbol{C}}$ and $\boldsymbol{C}_{\boldsymbol{v}}$ for nodular cast iron as compared to current tests on GJS-500. The graph is from [5].

\section{Summary and Conclusions}

Three point bending tests on $\mathrm{V}$-notched specimens machined from a component cast in ENGJS 500-14 nodular iron solid solution strengthened by silicon have been carried out. The $3 \mathrm{P}$ bending tests were performed at different stroke speeds $\left(10^{-3} \sim 10^{2} \mathrm{~mm} / \mathrm{s}\right)$. The resulting strain rates at the $\mathrm{V}$ notch varied in the range of $1 \cdot 10^{-4} \sim 5,8 \mathrm{~s}^{-1}$.

EN-GJS 500-14 has an increased brittle behavior with increasing strain rate. Predominately ductile fracture was observed for the strain rates $1 \cdot 10^{-4} \sim 4 \cdot 10^{-2} \mathrm{~s}^{-1}$. At the strain rate of about $1 \mathrm{~s}^{-1}$ more significant change in ductile to brittle fracture is seen. At the estimated strain rate of $300 \mathrm{~s}^{-1}$ for Charpy test complete brittle failure occurred.

The $3 \mathrm{P}$ bending tests at $-15^{\circ} \mathrm{C}$ showed predominately brittle fracture for the strain rates investigated $3,6 \cdot 10^{-2} \sim 2,3 \mathrm{~s}^{-1}$.

\section{References}

1. L. E. Björkgren and K. Hamberg, In proceeding of 2003 Keith Millis symposium on ductile cast iron, USA, Oct 20-23, (2003), pp. 70-90.

2. R. Larker, China Foundry, Nov. (2009), pp. 343-351.

3. T. Ikeda, T. Umetani, N. Kai, N-A Noda, and Y. Sano, ISIJ International, Vol. 56 (2016), No. 5, pp. 868-874.

4. R. Sandström and Y. Bergström, Metal Science Vol. 18, April (1984), pp. 117-186.

5. K. Wallin, Int J of Metalcasting/Vol. 8, Issue 2, (2014), Pp.81-86. 